\title{
DUAS FORMAS DE SE OUVIR O SILÊECIO: REVISITANDO 4'33"
}

\author{
Fábio Akcelrud Durão* \\ fad2@duke.edu
}

\begin{abstract}
When nothing is securely possessed one is free to accept any of the somethings. (John Cage, "Lecture on Something")
\end{abstract}

\begin{abstract}
RESUMO Após tecer rápidas considerações sobre arte e nada, o presente texto reinterpreta o 4'33', de John Cage, no atual contexto de superprodução semiótica. Salienta-se que, ao invés de ser uma abertura para a vida, a peça depende tanto de uma justificativa teórica, quanto de uma disposição formal. Vem desta uma dupla possibilidade, pois o silêncio de 4'33" pode ser tanto concebido como o objetivo (impossível) a ser alcançado, quanto um meio para se interromper o falatório das coisas. Correspondendo a estas duas possibilidades estão diferentes estruturas de dissociação de meios e fins: a busca concentrada e uma passividade agressiva. Estas duas posturas são relacionadas no texto ao estado atual do capitalismo, caracterizado por uma superprodução mercantil de signos.
\end{abstract}

Palavras-chave Silêncio; Nada; Superprodução Semiótica; Capitalismo

ABSTRACT After briefly dwelling on the relationship between art and nothing(ness), the essay interprets John Cage's so-called silent piece, his

* Professor do Departamento de Letras Anglo-Germânicas da UFRJ. Artigo recebido em 15/09/05 e aprovado em 15/11/05.

KRITERION, Belo Horizonte, $n^{0}$ 112, Dez/2005, p. 429-441 
much-commented 4'33", in the context of today's semiotic overproduction. It posits a twofold way of listening to the piece, insofar as silence may be conceived either as the (impossible) aim to be reached by listening, or as a means to interrupt the continuous blabbering of things. Underlying these two possibilities there are different dispositions of means and ends, namely a concentrated search for something and an aggressive passivity. These two postures are related in the text to the current state of capitalism, characterized as it is by a commodified overproduction of signs.

Keywords Silence; Nothing(ness); Semiotic Overproduction; Capitalism

\section{I}

A relação entre arte e nada pode ser muito grosseiramente descrita por meio de três modelos historicamente distintos. Há, em primeiro lugar, ${ }^{1}$ a idéia segundo a qual a arte é arrancada do nada. Os materiais brutos - a pedra, o som, a tela, ou o papel - perderiam sua insignificância à medida que se tornassem artefatos, que fossem compostos. Não importa tanto, neste contexto, se a emergência do sentido é concebida como surgindo puramente da subjetividade do artista, ou da tensão mais ou menos dialética entre uma materialidade inerte e as leis formais de estruturação da obra; o que é relevante em ambos os casos é o abismo entre a matéria morta de antes e o resultado subseqüente, dotado de espírito. Sob esta perspectiva, a frase, tão repetida por alguns artistas, de que a pedra já conteria em si, desde o começo, a estátua, a tela o quadro, o palco a peça, não faz sentido: não representa senão a racionalização de um processo que na maioria das vezes é penoso e sofrido, pois, entre o nada da matéria-prima e a completude da obra, há sempre o trabalho humano, o dispêndio de esforço, seja ele concebido como o da naturalidade do gênio, ou o da perfectibilidade do ourives.

Uma segunda possibilidade residiria não em moldar o nada, mas em expressá-lo. A arte seria, neste caso, responsável pela apresentação concreta do vazio da existência, da falta de sentido da vida. Sua disposição formal teria o mérito de organizar mais claramente uma ausência de finalidade que, no mundo extra-estético, ficaria ocultada pela pequenez do dia-a-dia, por projetos pessoais mesquinhos ou pela preocupação com a vida dos outros. O nada deixa,

1 Desconsideram-se, aqui, as teorias estéticas da Antigüidade, uma vez que lá se tratava de uma relação com o caos primordial, e não com o nada, conceito tipicamente moderno. 
assim, de ocupar o lugar inicial da composição artística, para situar-se, ao contrário, como seu télos. $\mathrm{O}$ terceiro modelo, finalmente, aquele que nos interessa, daria ensejo a um tipo de arte mais substancialmente tributária do nada; diferentemente de uma estética do nada, como nos dois primeiros casos, corresponderia a uma estética de nada: a realização de obras com o mínimo de materialidade, feitas virtualmente de vazio. Nem mais princípio, nem mais fim, nada passa a ser seu próprio conteúdo. E com isso fica difícil dissociar a arte de nada (como bem mostra o duplo sentido da expressão em português) de uma idéia de crise generalizada da arte.

No século passado, os exemplos de tal estética foram vários, oriundos de diversos gêneros artísticos, e estenderam-se por várias décadas - prova da persistência do problema. Na pintura, basta apenas pensar no Carré blanc sur fond blanc, de Kazimir Malevitch, a representação de uma tela branca sobre uma tela branca; ou nos quadros todos brancos ou todos negros de Robert Rauschenberg, regularmente repintados para que mantivessem sua brancura e pretura. Mas mesmo no Fontaine, o famoso urinol de Marcel Duchamp, algo de nada pode ser sentido, na medida em que ele é mais um gesto do que um objeto, a transposição de um artefato íntimo de higiene pessoal para o espaço público e representativo do museu. Na literatura, também, não seria difícil fornecer exemplos. O caso mais óbvio talvez fosse o daqueles poetas do silêncio, tais como Paul Celan; no entanto, um nada pode igualmente ser constatado em seu oposto dialético, como na prosa verborrágica de um Samuel Beckett, que, em "romances" como O Inominável, ou contos como "Ping," consegue encher páginas e páginas com palavras, mas que, pela repetição e pela produção de sua incoerência, perdem o sentido. Passam a assemelhar-se a meras cadeias de som, significando nada ou quase nada. ${ }^{2}$

É claro, cada um destes casos possui sua própria poética subjacente, seja aquela com a qual trabalhava o artista, seja a que a crítica fez tornar-se lugar comum. Que tais teorias possam ser não apenas inadequadas, mas estar por vezes em contradição flagrante com o conteúdo real das obras, não é algo que deveria espantar, pois é próprio da arte não se adequar facilmente a projetos artísticos, e, como prática que é, discordar das idéias que lhe deram origem (uma boa discussão disso é fornecida por Compaignon 1990, p. 79-110). Se há, assim, sempre algo de a posteriori no julgamento estético; se ele é sempre uma reconstrução post-factum de algo que muitas vezes escapa ao artista e a seus contemporâneos, isto é ainda mais aparente em relação às obras que tomam

2 Talvez isso possa ser generalizado para o serialismo na literatura como um todo. Cf. e.g. The Making of the Americans, de Gertrude Stein. 
o nada como seu ponto de partida: a provisoriedade do juízo estético aqui é ainda mais definitiva.

Some-se a isso, no entanto, uma outra dificuldade, típica do comentário ao nada. Sua crítica move-se em um paradoxo: por um lado, há uma resistência do nada à explicação e à elaboração conceitual. Como abordar, e justificar, um pedaço de pedra, intocado? Como fazer uma análise formal do urinol de Duchamp (separá-lo em partes constitutivas, investigar sua estrutura, determinar o balanço da composição) sem cair em ridículo? Em suma, como evitar a desproporção entre a seriedade, a avidez e a necessidade de sentido, típicos do discurso teórico, e a irreverência, o desprendimento e a recusa a significar desse tipo de arte? É a própria materialidade imaterial da arte de nada que impede que ela se torne um monumento, enquanto a crítica, já na seleção que efetua, o pressupõe. Por outro lado, justamente porque a matéria-prima desta forma de produção estética é feita de nada, as obras dependem visceralmente das palavras da crítica para que seu estatuto artístico seja reconhecido e validado. Já que por si sós passariam despercebidas, dissolvidas no fluxo das coisas, necessitam intrinsecamente de um gesto exterior de legitimação. É como se, invocada, a própria reflexão fizesse agora parte da obra, mostrando-se indispensável para que esta se torne aquilo que é. Inerentemente inadequado e estruturalmente imprescindível, o discurso crítico vê-se contaminado pela crise da arte, que outrora julgava poder diagnosticar tão soberanamente.

Com efeito, trata-se aqui de uma daquelas situações nas quais uma reviravolta dialética se faz necessária; quando, em vez de se tentar obter uma saída para um impasse, o próprio problema torna-se o ponto de partida e objeto de investigação. Daí a hipótese de leitura subjacente a este texto: a de que a complexidade da relação atual entre crítica e arte, conceito e impulso mimético merece ser lida dentro do contexto de uma questão contemporânea mais ampla, à qual a arte estaria de alguma forma reagindo - a questão da superprodução semiótica, da ocupação total do mundo, tanto geográfico quanto psíquico, por uma quantidade nunca antes vista de mensagens; o império absoluto da linguagem, no qual é cada vez mais difícil evitar o sentido repetido, não significar (um exemplo: quando se vestir despreocupadamente não é mais visto como ignorar a moda, mas como produzir a despreocupação). Uma vez que é colocada no centro da investigação, a supreprodução semiótica põe em cena uma constelação sui generis de problemas. Em primeiro lugar, ela tem como sua precondição o salto tecnológico da terceira revolução industrial e corresponde a uma nova fase de acumulação capitalista, como argumenta Fredric Jameson (1991, p. 274-278), para quem as novas mídias têm uma relação intrínseca com o mercado, a ponto de os dois serem praticamente 
intercambiáveis. Devido à sua ubiquidade e repetição, a superprodução semiótica promove um enfraquecimento do poder apelativo da linguagem (de sua força ilocucionária na terminologia de Austin [1975]), e cujo exemplo mais contundente é o do modo imperativo de todos os comerciais. Os diversos tipos de enunciados, independentemente de seu conteúdo, tendem a ser recebidos da mesma forma, ${ }^{3}$ corroborando dessa maneira a idéia de Slavoj •i•ek (e.g. 1994, p. 310-331) de que a ironia e o distanciamento cínico seriam os grandes males de nossa época, aos quais é claro, dever-se-ia adicionar a anomia, a incapacidade de relacionar linguagem e ação. E como, para seguir Türcke (2002), a própria noção de ser aproxima-se do ideal de emitir de signos (sua fórmula: "ser é ser visto"), a superprodução semiótica passa a interferir igualmente na maneira como os indivíduos vivenciam sua existência, sentindose como nada se não vistos, ambicionando até as últimas fibras de seu ser o estado de celebridade. Por fim, tudo isso aponta para uma dialética da natureza no âmbito da significação. Se a produção de sentido é uma atividade tipicamente social, que transforma materiais naturais para fins humanos, então haveria boas razões para se transpor o processo descrito por Adorno e Horkheimer na Dialética do Esclarecimento (1985) para a esfera da linguagem em sua fase de superprodução, quando o mundo completamente humanizado reproduz o terror primitivo diante do estranhamente outro da natureza - como na sensação de desamparo diante da selva de avisos luminosos em neon, à noite, em qualquer metrópole do sistema global. ${ }^{4}$

É claro, estas questões não podem ser desenvolvidas no escopo deste texto; elas chamam a atenção, contudo, para o lugar privilegiado da música neste estado de coisas. Se é possível caracterizar como ruído/barulho o que é gerado pela superprodução de signos e mensagens, então a música, a disciplina de organização dos sons, deverá ser um âmbito privilegiado de investigação. De fato, não é outra coisa que defende Attali (1985) em um excelente livro, ao descrever a condição atual de reprodução da música, caracterizada pela repetição, um conceito muito próximo do de superprodução semiótica. Como enfatiza Jameson em seu prefácio ao texto, Attali, diferentemente de Adorno e

3 Como na anedota contada por John Cage em um texto chamado "Indeterminação": "Fui ouvir Krishnamurti falar. Ele estava palestrando sobre como se ouvir uma palestra. Disse: 'Você tem que prestar toda atenção ao que está sendo dito e você não pode fazer isso se estiver tomando notas.' A senhora do meu lado direito estava tomando notas. O homem do seu lado direito cutucou-a e disse: 'Você não ouviu o que ele disse? Você não deve tomar notas.' Ela então leu o que havia escrito e disse: 'Está certo, eu já escrevi isso aqui nas minhas notas." (Cage, 1961, p. 269)

4 Seria interessante investigar o quanto a superprodução lingüística promove a socialização da sociedade, sua maior coesão (ainda que antagônica) e seu espessamento. Correspondendo ao princípio de troca, utilizado por Adorno, o conceito de interpelação seria útil aqui, contanto que fosse adaptado em sua matriz althusseriana (Althusser, 1995) para adequar-se à linguagem das mercadorias e não mais à do Estado. 
a grande maioria dos filósofos da música, não apenas vê nas manifestações sonoras uma via de acesso à totalidade social, mas identifica nelas um poder profético, na medida em que exibiriam, antecipadamente, o que só depois seria perceptível na política e na economia. É sob este pano de fundo que a leitura de uma peça aparentemente insignificante assume uma relevância talvez inusitada.

\section{II}

A mais conhecida das obras de nada, o 4'33" de John Cage, é sem dúvida a mais polêmica de todas elas..$^{5}$ A peça, composta em 1952, pode ser executada por qualquer grupo de instrumentos; ela é dividida em três movimentos de duração desigual (na primeira performance 30', 2'23', e 1'40") durante os quais o(s) intérprete(s) não toca(m) nada. Algum sinal dever ser dado para indicar o início e fim de cada movimento - fechando a tampa do piano, por exemplo, para determinar o começo de cada movimento e abrindo-a ao seu término (ou vice-versa). Recomenda-se (cf. Solomon, 2001) que o(s) instrumentista(s) esteja $(\mathrm{m})$ concentrado(s), e que marque $(\mathrm{m})$ o tempo e vire $(\mathrm{m})$ corretamente as páginas, brancas, da partitura. ${ }^{6}$ Por outro lado, desconselhase que outras atividades sejam realizadas durante a obra, como uma dança por exemplo.

A situação que teria dado a idéia a John Cage para a compor 4'33" é das histórias mais citadas na música contemporânea, ainda que não tenha perdido seu caráter meramente anedótico:

Com efeito, por mais que tentemos, não conseguimos fazer o silêncio. Para certos fins de engenharia, é desejável ter uma situação tão silenciosa quanto possível. Tal recinto é chamado de câmara anecóica, suas seis paredes são feitas de um material especial, um quarto sem ecos. Entrei em um destes na Universidade de Harvard há vários anos atrás e ouvi dois sons, um alto e o outro baixo. Quando os descrevi para o engenheiro encarregado, ele me informou que o alto era o meu sistema nervoso em operação, o baixo, meu sangue circulando. Até que eu morra haverá sons. E eles continuarão depois de minha morte. Não é necessário temer pelo futuro da música. (1961, p. 8)

5 Isso tem muito a dizer a respeito da posição da música no mundo contemporâneo. Que o público não se espante diante de um quadro em branco, mas que não possa tolerar a ausência de som, corrobora o que Adorno (1991) já há algum tempo chamava de regressão da audição.

6 A partitura original foi perdida. Em 1962, Cage compôs uma segunda parte de 4'33" chamada 0'00", ou 4'33" No.2. A "partitura" aqui consiste simplesmente da indicação: "Em uma situação dotada do máximo de amplificação (sem retorno), execute uma ação disciplinada, com qualquer tipo de interrupção, de forma a cumprir uma obrigação, total ou parcial, para com os outros. A mesma ação não deverá ser repetida em execuções diferentes, e a ação não poderá ser a de uma 'composição musical'. Não se deve dar atenção à situação (eletrônica, musical, teatral)." 
O silêncio absoluto não pode ser ouvido; quanto mais se procura alcançálo, mais os sons ambientes assumem relevo. É por isso que chamar 4'33" de peça silenciosa ou peça-silêncio (silent piece) tem algo de enganoso, na medida em que a obra visa, de fato, aos sons que necessariamente existirão em qualquer situação concreta de execução. Trata-se, assim, de um enquadramento sonoro, cuja estrutura deve ser investigada em relação a condições sociais concretas do mundo - um tipo de silêncio bem diferente do antropológico-cultural descrito por Le Breton (1997), por exemplo, tão variável que se transforma em invariante.

Antes disso, porém, vale a pena chamar a atenção para a dependência de discurso deste experimento, que simplesmente não teria sentido sem as explicações de Cage em Silence, assim como para a quantidade imensa de palavras (também elas sons ou ruídos) que foram escritas para comentar 4'33". O descompasso mencionado anteriormente (para o qual, sem dúvida, de alguma forma contribuo) entre um nada da obra e o barulho da crítica não poderia ser mais flagrante. Dificilmente se evita uma sensação de desconforto ao se ler, por exemplo, a discussão de Solomon (2001) a respeito das diversas edições e partituras da peça: uma prática filológica rigorosamente de nada, que produz um monumento de vazio. Em outros casos, no entanto, o comentário contrubui para a configuração de um nada mais satisfatório, ainda que não consiga se desvencilhar por completo do paradoxo que lhe é imanente. Perloff (1981, p. 288-339), por exemplo, situa John Cage, e 4'33" em especial, em uma corrente da arte moderna caracterizada pela indeterminação, contrastando com a tendência dominante do Alto Modernismo, oriunda do simbolismo, e que se estenderia de Baudelaire e Mallarmé até T. S. Eliot, Auden, Stevens e Frost. O nada de Cage fica aqui solidamente ancorado em uma tradição de experimentalismo, junto com nomes como Rimbaud, Gertrude Stein e Beckett.

Terra (2000, p. 51-66) discute a indeterminação de 4'33"' de um ponto de vista mais instrinsecamente musical. Determina como horizonte inicial da peça o debate de meados do século XX acerca de que direções a música deveria tomar em relação ao legado do dodecafonismo, em especial quanto ao serialismo integral. Identifica as origens da peça em Erik Satie (como aponta o próprio Cage [1961, p. 76-83]) e principalmente em Webern, com sua idéia de uma série de doze sons que não fosse imediatamente trabalhada na partitura, mas que tivesse algo de virtual, pairando por sobre as notas escritas e sendo evidenciada por seus efeitos sonoros. 4'33" remeteria, dessa maneira, à exaustão do serialismo, que nada mais era do que a radicalização do princípio da série dodecafônica, agora estendido para todas as variantes musicais, como o ritmo e a dinâmica, e não apenas a altura, as notas propriamente ditas. A crítica de 
Cage é a de que na base da idéia de série falta o zero, a ausência ou nada. Falta a falta:

Curiosamente, o sistema de doze sons não tem o zero em si. Dada uma série: 3, 5, 2, $7,10,8,11,9,1,6,4,12$ e o plano para se obter sua inversão, por meio de números que, quando somados aos correspondentes da série original, vão gerar 12, obtém-se 9 , $7,10,5,2,4,1,3,11,6,8,12$. Pois neste sistema 12 mais 12 é igual a 12. Não há suficiente nada nele. (1961, p. 79)

É justamente este nada que daria a abertura da música para aquilo que estivesse fora das meras notas da partitura, que para Cage corresponderia aos sons do mundo. 4'33" é feito interamente deste nada; é ele que permite que os sons da sala de concerto possam ser percebidos como música. E como estes sons não podem ser previstos ou controlados, a intencionalidade e o controle subjetivo do material musical, levado às últimas conseqüências com o serialismo, ficam fora de questão.

No entanto, como já foi apontado no começo, esta configuração de nada, a transformação dos ruídos do mundo em música, não poderia ocorrer sem uma justificativa teórica, para além de toda e qualquer estruturação imanente à obra (uma estrutura que, como veremos, existe de fato). No caso de Cage, a teoria subjacente à 4'33" é o Zen, ${ }^{7}$ sua filosofia de aceitação de mundo assim como ele é, e da rejeição, que lhe acompanha, de se possuir coisas:

Nossa intenção é a de afirmar esta vida, não de trazer ordem ao caos, nem de sugerir aprimoramentos à criação, mas simplesmente de despertar para a própria vida que estamos vivendo, que é tão excelente, contanto que se coloque a mente e os desejos fora de seu caminho e que se a deixe agir por sua própria vontade. (1961, p. 95)

A influência da filosofia oriental em Cage pode muito facilmente iludir o leitor, pois, como afirmou Patterson (2002a, p. 43) trata-se "de um tipo particular de apropriação por meio do qual os elementos básicos e a estrutura unificadora de uma idéia são mantidos, embora o efeito visado seja primeiramente solapado [undercut] e então revertido (i.e. subvertido) por uma motivação contrária ao objetivo inicial da idéia.” Esta estrutura de apropriação continuará a ser válida posteriormente, quando, ainda na década de 1960, Cage iria buscar inspiração teórica em outras fontes, mais preocupadas com temas sociais, como em Henry David Thoreau, Marshall McLuhan e Buckminister Fuller (Patterson 2002b, p. 88-91). A justificativa para a transição não deixa de ser engenhosa:

7 Cage já flertava antes disso com outras vertentes do pensamento oriental, como o de Ananda Coomaraswamy (Patterson, 2002a, p. 48-50). 
Para mim, isso significa que as disciplinas, gradativa e repentinamente (principalmente as orientais), antes praticadas por indivíduos para pacificar suas mentes, pondo-as de acordo com a realidade atual, devem agora ser praticadas socialmente - isto é, não só dentro de nossas cabeças, mas também fora delas, no mundo, onde nosso sistema nervoso central de fato está agora. (Cage, 1985, p. xxv)

Patterson não se questiona, porém, a respeito da possível necessidade de uma justificativa teórica desajustada para a produção de obras como 4'33”, nem das consequiências possíveis desta escolha específica de base teórica. Está claro que esta aceitação da vida é também uma aceitação da desigualdade e da opressão, ${ }^{8}$ mas para além disso, há um paradoxo no fato de que

ao romper com o tempo medido, deixando de submeter os sons à pulsação e ao compasso, recusando fazer da música um objeto que se desenvolve no tempo, fazendo dela um processo que se inicia e termina em qualquer ponto e a qualquer momento, Cage acaba recorrendo a Cronos [a temporalidade linear, F. A. D.] para traçar os limites temporais em que a música irá acontecer. Ao recusar Cronos, Cage acaba por submeter-se a seus domínios. (Terra, 2000, p. 103)

À ambição de promover uma abertura total para a riqueza incontível do mundo corresponde uma obediência total à linearidade do tempo medido, os quatro minutos e trinta e três segundos. Ao enfatizar a construção linear da situação de silêncio, este comentário oferece uma boa mediação para se pensar de que modo o vitalismo pode funcionar como um elo de ligação entre as "reflexões" de Cage (elas mesmas, por vezes, concebidas como obras, a ser lidas com estruturas rítmicas próprias e obedecendo ao relógio) e as elaborações mais propriamente teóricas da crítica e da estética. ${ }^{9}$ Esta filosofia da vida é equivocada, pois ela supõe uma disponibilidade do material sonoro que não existe. Os sons não estão à disposição dos ouvintes, mas devem ser construídos; surgem apenas como resultado de algum tipo de trabalho ou elaboração, como veremos a seguir.

Antes disso, no entanto, cabe salientar que estes dados problemáticos vão lado a lado de um conteúdo contestador. Em primeiro lugar, deve-se lembrar

8 "Fui a um concerto lá no Town Hall. O compositor que tinha as obras apresentadas forneceu notas para o programa. Uma destas notas dizia que há muita dor no mundo. Depois do concerto, eu estava andando com ele e ele me dizia que as execuções não haviam sido de seu agrado. Então eu disse, 'Bem, eu gostei da música, mas não concordo com a nota do programa dizendo que existe dor demais no mundo.' Ele disse: 'O que? Você não acha que há dor demais?' Eu disse: ‘Acho que há a medida certa.”' (Cage, 1961, p. 93)

9 E.g. "O silêncio significa, em Cage, a própria Vida; o universo sonoro que nos rodeia num constante fluir." (Santos, 2004, p. 80); "Este campo, em que os eventos sonoros se configuram de modo imprevisível e cambiante, constitui o tecido comum entre música e vida." (Terra, 2000, p. 54); "O trabalho de um intérprete é assim recolocado na própria vida, e especialmente na vida da sociedade: determinar o que é correto fazer, agir de forma a avançar o bem geral. A música interpenetra a vida." (Brooks, 2002, p. 224) 
que a duração da peça representa uma referência consciente da parte de Cage à música de sucesso. 4'33" é um tempo aproximado ao do hit parade da época e a produção do silêncio apresenta-se assim como seu rigoroso contrário. Em segundo lugar, é importante salientar que a emergência dos sons do ambiente é o justo oposto do som ambiente, o fluxo contínuo, indistinto, praticamente não percebido, mas imposto, de ruído (cf. Attali [1985, p. 111-112]). Mas ele é também o oposto do monólogo interno, a versão psicológica da superprodução semiótica. ${ }^{10}$

Este potencial crítico de uma obra que, segundo seu autor e grande parte dos críticos, deveria ser totalmente afirmativa, abre uma nova perspectiva de interpretação. 4'33" apresenta-se nesse contexto como um experimento de resistência à superprodução semiótica. $\mathrm{O}$ caráter contestatório da música de Cage já havia sido notado por Adorno em um importante ensaio, como "protesto contra a cumplicidade obstinada da música e domínio da natureza" (Adorno, 1978 , p. 534); no entanto, argumenta em seguida que o poder de negação do gesto aleatório, segundo ele expressão neo-dadaista da anti-arte, é facilmente absorvido pela sociedade: "Action painting, action composing são criptogramas da ação direta, que se tornou impossível; surgiram em uma época na qual tais ações seriam impedidas pela técnica ou contidas [aufgefangen] pela administração." (Adorno, 1978, p. 535) Ainda que, sem dúvida, correta, a observação de Adorno tem como base a ação concebida como gesto de repúdio vazio. ${ }^{11}$ Mas não é exatamente isso que está em jogo em 4'33”, pois o tipo de ação exigido do público é estruturado.

A peça chama a atenção, antes de mais nada, para o trabalho exigido pela busca do silêncio. O estilo simples da escrita de Cage na descrição de sua experiência na câmara anecóica é enganoso: imagine-se o grau de concentração necessário para extinguir todo o pensamento para se focalizar o silêncio e acabar ouvindo seu sistema nervoso e sua corrente sangüínea. Isso aponta para uma dificuldade real de execução de 4'33', muito facilmente passada em silêncio por comentaristas, pois em sua forma ideal ela aconteceria em um ambiente fechado no qual todo o público se dedicasse ao máximo para ouvir o silêncio, para poder escutar aos sons gerados por todos. Risinhos ou brincadeiras, típicas resistências à falta de ruído, põem por água abaixo a

10 Esta seria uma interessante hipótese para a historicização do monólogo interior na literatura (também chamado de fluxo de consciência). A novidade desta técnica de representão no Ulisses de James Joyce ou na Mrs. Dalloway, de Virginia Woolf, estaria relacionada a um processo de proliferação de mensagens já nas primeiras décadas do século passado.

11 É interessante comparar a visão de Adorno sobre Cage com a de Heinz-Klaus Metzger, seu aluno e muito respeitado por ele, que escreveu um texto chamado "John Cage, or Liberated Music" (1997). Para a recepção de Cage na Alemanha (tendo Adorno como fio condutor) cf. Pepper (1997). 
performance. Um 4'33' bem-sucedido pressupõe um público disciplinado. A intencionalidade, tão triunfalmente abandonada no processo de composição, cobra uma revanche na esfera da recepção. Trata-se de uma forma de resistência e oposição baseada na força, no ímpeto subjetivo e em uma vontade de ferro, no qual um crítico cético veria similaridades com o espírito empreendedor.

O retorno da intencionalidade nesse contexto tem implicações contundentes para discussões mais amplas. Se boa parte do discurso pós-moderno se sustenta sobre a idéia de riqueza do mundo, de sua abundância sem limites (cf. Durão, 2003), 4'33" mostra o trabalho necessário para que tal riqueza possa ser obtida. Já em relação à critica musical, a peça problematiza a possibilidade de simplesmente ouvir o ambiente, como quer Santos (2004), que, partindo de Cage, acredita poder tornar, sem mais, os barulhos da cidade em música. Vem daí uma interessante nova dimensão estética, inaudita até agora, pois a direção da produção de sentido assume aqui um caráter determinante. Se, por um lado, qualquer objeto pode ter uma natureza artística em um museu (como vimos, cabe à crítica determiná-la), não importa qual seja o artefato (a Mona Lisa, o David de Michelangelo etc.); por outro, ele não será arte quanto for repetidamente oferecido aos sujeitos. No capitalismo da superprodução semiótica, o fluxo das mensagens não parte dos sujeitos em conjunto, mas lhes é conjuntamente imposto. Necessariamente, a postura inicial é de defesa. Ao produzir uma situação de silêncio, 4'33"'estaria revertendo a direção do acesso aos sons: ao invés de se ter os aparatos reprodutores/repetidores dirigindo-se aos sujeitos, ter-se-ia os sujeitos buscando os sons. No primeiro caso, são agentes de violência e alienadores; no segundo, revestem-se de utopia.

Isso permite, no entanto, que uma outra perspectiva surja, quando se muda o foco da reflexão, situando-o não mais no plano da busca subjetiva, mas no da produção de objetos. Se a superprodução ininterrupta de signos e mensagens, o barulho, é dada, então o silêncio de 4'33" pode assumir uma outra natureza. Ao invés de ser o objetivo, estruturalmente impossível, a ser almejado por sujeitos produtores de sons, ele passa agora a representar um meio, a imposição de uma ruptura, marcada, por exemplo, pelo pianista fechando (ou abrindo) a tampa do piano. A interrupção abrupta do falatório das coisas causa primeiramente um impacto de estranhamento: da mesma forma que se sente um vazio quando um som contínuo é interrompido (um alarme de carro, uma britadeira), ouve-se aqui, sim, o silêncio. A esta sensação de desnorteamento segue-se uma adaptação, relaxada e aliviada, ao ambiente, e os sons produzidos pelas pessoas podem ser ouvidos pelo que são. Como não há busca, os risos tensos não têm razão de ser e, mesmo que existam, não precisam ser negados. 
Seria equivocado ter de optar por uma destas duas maneiras de se ouvir o silêncio. Mais interessante é subir um degrau e ouvir a tensão, dentro de 4'33'”, entre essas formas de nada. O ímpeto subjetivo da primeira e a agressiva passividade da segunda representariam formas distintas de se opor ao barulho do mundo, resultado da superprodução semiótica. É desnecessário enfatizar o que há de crucial nisso. Como em tantos outros casos, encontram-se misturados o melhor e o pior, pois, dependendo do resultado de 4'33", dois cenários se descortinam. Ao fracassar, vence o barulho, que continua a sê-lo; se bemsucedido, transformam-se os ruídos em música, e os ouvintes, em músicos.

\section{Referências}

ADORNO, Theodor Wisengrund. O fetichismo na música e a regressão da audição. 5. ed. São Paulo: Abril Cultural, 1991. (Col. Os Pensadores) Vers une musique informelle. In: . Gesammte Schriften. Frankfurt a. M.: Suhrkamp, 1978. v. 16. ADORNO, Theodor Wisengrund; HORKHEIMER, Max. Dialética do Esclarecimento. Trad. Guido Antonio de Almeida. Rio de Janeiro: Zahar, 1985.

ALTHUSSER, Louis. Ideologie et appareils ideologiques d'État. In: Sur la reproduction. Paris: Presses Universitaires de France, 1995.

ATTALI, Jacques. Noise: the political economy of music. Trad. Brian Massumi. Minneapolis: Minnesota U.P., 1985.

AUSTIN, J.L. How to do things with words. 2. ed. Cambridge: Harvard U.P., 1975. BROOKS, William. Music and society. In: NICHOLLS, David (Ed.). The Cambridge Companion to John Cage. Cambridge: Cambridge U.P., 2002.

CAGE, John. Silence. Middletown: Wesleyan U.P., 1961.

. De Segunda a um ano. Trad. Rogério Duprat. São Paulo: HUCITEC, 1985. COMPAIGNON, Antoine. Les cinq paradoxes de la modernité. Paris: Seuil, 1990. DURÃO, Fabio Akcelrud. A. A postmodern paradox. Revista Eletrônica Outras Palavras, v. 3, 2003. Disponível em: <http://orbita.starmedia.com/outraspalavras/ volumes.htm>.

JAMESON, Fredric. Postmodernism; or, the cultural logic of late capitalism. Durham: Duke U.P., 1991.

LE BRETON, David. Du Silence. Paris: Métailié, 1997.

METZGER, Heinz-Klaus. John Cage, or Liberated Music. October 82. Trad. Ian Peper, 1997.

NICHOLLS, David (Ed.). The Cambridge Companion to John Cage. Cambridge: Cambridge U.P., 2002.

PATTERSON, David W. Cage and Asia: history and sources. In: NICHOLLS, David (Ed.). The Cambridge Companion to John Cage. Cambridge: Cambridge U.P., 2002a. 
PATTERSON, David W. Words and writings. In: NICHOLLS, David (Ed.). The Cambridge Companion to John Cage. Cambridge: Cambridge U.P., 2002 b.

PEPPER, Ian. From the Aesthetics of Indifference to Negative Aesthetics. October 82, 1997.

PERLOFF, Marjorie. The Poetics of Indeterminacy: Rimbaud to Cage. Illinois: Northwestern U.P., 1981.

SANTOS, Fátima C. Por uma escuta nômade: a música dos sons da rua. São Paulo: EDUC/FAPESP, 2004.

SOLOMON, Larry J. The sounds of silence. 2001. Disponível em: <http:// www.music.princeton.edu/ carson/4'33.htm>. Acesso em: 16 ago. 2005.

TÜRCKE, Christoph. Erregte Gesellschaft: Philosophie der Sensation. München: Beck, 2002.

TERRA, Vera. Acaso e Aleatório na Música; um estudo da indeterminação na poéticas de Cage e Boulez. São Paulo: EDUC/FAPESP, 2000.

ŽIŽEK, Slavoj. How did Marx invent the symptom? In: ŽIŽEK, Slavoj (Ed.). Mapping Ideology. Londres: Verso, 1994. 